\title{
The Challenges of Using Integrated Technology in the Classroom
}

\author{
Kish Gué
}

\begin{abstract}
In this interview, ICT consultant Kish Gué shares his thoughts on how teachers can integrate technology in the classroom. In view of ever-changing technological advances, he believes that teachers should switch to learning at the same time as their students as opposed to teaching them about technology. He provides examples of projects that have successfully integrated technology and gives advice to novice teachers on how to best use technology in their teaching. He explains that parents have an important role in ensuring that their kids become good "digital citizens" who use the Internet safely and responsibly. Finally, he shares what his own daughter has taught him about technology.
\end{abstract}

You are the "RÉCIT" person from the English Montreal School Board (EMSB). Can you talk about what this involves and how you ended up in this position?

RÉCIT ${ }^{1}$ is a network of pedagogues. Their mandate is to promote the integration of technology in the schools. There are different levels of RÉCIT members. There is the local level-that's what I am: someone in charge of sharing all the resources gathered by RÉCIT in their school board. So, there's one for every school board in the province of Quebec. Then we have the national members who are composed of only one person per subject matter for the whole province. They also have the same mandate, but they do it at a provincial level. They work a lot with us and build a lot of resources and websites-interesting pedagogical resources that we can use with teachers and students in our school boards. We also have the FGA, ${ }^{2}$ which is "Formation générale des adultes," so you also have RÉCIT in charge of the adult sector as well as one RÉCIT person for all the private schools.

How did I end up being a local RÉCIT? I was actually hired as an information, communications, and technology (ICT) consultant with the board. Someone else has the official RÉCIT title at the EMSB - her name is Caroline Dupuis. But she was on loan from the Ministry and I ended up replacing her for the last four years. She's probably going to come back and I'm going to go back to becoming a regular ICT consultant, but for now I wear both hats.

What did you do before you were doing this?

Before this I was a teacher and started teaching in 1998. I taught in elementary schools at all grade levels and loved it. I started integrating technology very rapidly because I saw the value and potential-the added value to the learning that was happening in the classroom with technologies. And I ended up becoming a consultant. I really started helping out the official consultants at the board that I used to work for, which was Riverside School Board ... and a position opened up. 
One of your strengths is your ability to work with students on projects. Can you talk about a few projects that stand out and indicate why they were so successful?

There are many projects, especially since I've become a RÉCIT employee. I have access to this wealth of knowledge and resources by other pedagogues that are part of RÉCIT. Being in touch with the national RÉCIT organization, I also have access to every document and resource that they produce. They come up with a lot of good ideas for projects. What I like is that it's always done with the focus on pedagogyand not on the technology. Technology is a great component, but it's not the end goal: we don't want to make our students people that are good at using computers, but rather people that are more and more proficient at learning whatever they're exposed to.

One big project is called "Culture à l'écoute," ${ }^{3}$ which would translate to "Tune Into Culture." We use the QR code technology ${ }^{4}$ and link those QR codes to podcasts that have been created by students. These students go around their community, look at historical and interesting landmarks, research them, and create a 45 -second podcast, which really is a 45 -second oral presentation. In these podcasts, they work on the language, on the "univers social," which is Social Sciences, and they use the technology. So, they create; they record their voice. I go in there and help the teachers and students understand how to use audio-editing software to create a nice oral audio file accompanied by images that they took themselves. What's great about that project-and many other projects-is that it's very purposeful. When the students do engage in those projects, they don't feel like they're doing work for their teacher-it becomes something real: there is a real audience out there that will benefit from their work. What's also great about that is that it gives them a sense of: "Even if I'm just a child, I have a lot power and can contribute positively to my community. My work can even benefit adults." And that is a great feeling because I feel that it gives them a taste of what they can do later in life. I'm not talking about audio files that are accessible, but in terms of what they can contribute. It's like planting an idea in someone's head: once you have an idea you'll probably end up acting on it. It's like the movie "Inception" with Leonardo DiCaprio: it starts with an idea-and for them it was much more than an idea, it was actually experimenting something that worked.

"Histoire de manga" ${ }^{5}$ was another great project. It was a comic strip influenced by the Japanese style. It was another project that was put together by LEARN-RÉCIT. LEARN is pretty much the same as the national RÉCIT, but for the Anglophone community. So, Histoire de manga ("The Story of Mangas"), which are Japanese animes or cartoons, was interesting for students because they thought of a story that they wanted to tell and it's always linked to the subject domains that they're working on. They had to think of a story, storyboard it, went ahead with iPads all around the school, took pictures that would be part of the manga, and then added filters with apps such as Comic Life. They add filters so that it becomes kind of cartoonish. But then we studied how the Japanese do it, the expressions that they have-there is a lot of focus on facial expressions. And all of that is integrated into one beautiful project at the end.

Some teachers feel very vulnerable when trying to use technology. What advice do you have for them?

Over the years, I've come to realize that teachers must have the courage to be vulnerable. It's not a bad thing to be vulnerable. There is a difference between being vulnerable and losing control: we're not 
talking about losing control, but rather surrendering control. I think that many people that went into teaching are people that like to control things, and are pretty good at organizing themselves, organizing their class, and planning. If something fails, they have a Plan B, and if Plan B fails they have a Plan C. When it comes to integrated technology, it's really hard because technology is very efficient, but it's not always reliable. And it does happen that sometimes it just doesn't work and you don't understand whyand you have to be comfortable with that fact. Technology develops so fast that it's impossible to know everything. Just from one version to another version things change. We have to be comfortable with understanding that we can't know everything, but that we can still try to use it, especially with our students. Our students themselves are able to learn and they will adapt. Let's do it with them and try not to learn everything before them, and then present the technology - that just can't happen for the reasons that I've mentioned. It's important to have the courage to just jump-and you know that you're going to end up swimming anyways; you're not going to drown.

It does happen that sometimes the whole lesson doesn't work and the technology didn't work, but that's actually also valuable because then you just figure out why it didn't work-and right there you know more. When I was a teacher, that's what I always did. At the beginning of the 2000 year, we got Apple computers that we called the Blue Bundies. They were transparent with colours: blue, green, pink. And with that computer came a software called iMovie. At first, we didn't know what it was, but our principal knew that we could make movies with it and bought two cameras for the school. I had no idea how to use it, but I knew that it would be interesting to use iMovie. So, I kept a few kids with me at lunchtime and we just figured it out, but all together. I don't have enough time to learn a technology by myself and then present it to my students. If I do that, my wife is not going to be too happy with me! That year, as soon as we figured it out, we saw the possibilities. We started doing little documentaries and by the end of the year we had produced a 30-minute movie on Great Civilizations. That was a crucial year for me to realize that we can learn with our students, but you have to be able to surrender control. You have to know that you cannot control every aspect of what's going to happen. Talking to many consultants, especially the ones in technology, we realized that we pretty much all shared that characteristic and personality trait: we don't have a problem with welcoming what's new; we just try. We don't try to learn everything in advance-it's not even possible to do.

Do you have any suggestions for a teacher who's a novice with technology on how to get started?

There are a lot of resources out there, especially on the Internet and social media. If you don't know how to do something, someone else does and that someone can easily be found on the Internet either through YouTube videos and online tutorials or through Twitter. There are so many great pedagogues on Twitter sharing what they're doing every day. Two weekends ago I was in New Hampshire with Alan November. ${ }^{6}$ He shared what a classroom did on Twitter. Little kids wanted to know how to create robots, but they didn't exactly know how ... so they connected to a classroom in Japan and the kids in Japan showed them how to do those robots. Social media is extremely powerful if we use it correctly. So, go on social media and find help online, and if you have someone in your school or someone in your milieu that can help you, do not hesitate to contact that person. 
I remember one of the first things that I wanted to learn when I was a teacher was how to have an image and text over the image-that's all I wanted. So, I went to the right person who was able to show that part to me. Once I understood how to do that, then I kept on looking for different interesting things to do. I really started engaging in projects and back there we had created a magazine just with image and text over it. Someone was there to help me, but I went out and looked for that person.

What do you suggest parents need to know about technology in order to keep their children engaged and safe?

Digital citizenship is a big dossier that pretty much all the school boards throughout the world are now looking into. By "digital citizenship," I mean how to use the Internet, not only in a safe way, but in a responsible way. The virtual world is very much there. Even if it's virtual, it's very real—and everything that happens on the Internet has an impact on their real physical life. Kids understand how to use the technology pretty well, but it doesn't mean that they use their judgment in the right way all the time. And that's where parents can have a huge impact: they don't need to know everything, but they have to understand how to help their kids make good decisions. Everything that you do in real life, you should act the same also online. The attitudes that we've seen of parents are very often, either they don't want to know anything about the Internet and they prevent their kids from using computers, or they say, "I don't know anything about computers," and they let them do whatever they want. Both attitudes I find are problematic. If you're way too restrictive, it doesn't mean that the student won't be exposed to the technology once they leave the household. And if you are too permissive, then we end up with the problems that we've had for the last few years. We have a whole generation of students that raised themselves with technology and on the Internet ... cyberbullying ... we see the problems. Parents, first of all, have to understand that computers and the Internet are very powerful, but they can be used in a very positive way ... what we call the "online reputation." It's hard to not be present on the Internet at all. We always leave traces and some traces are not even your own-it can be someone else that posted something on you. We have to make sure that what people see about us on the Internet reflects positively on us, instead of negatively. So, parents can play a big role.

If you were to design a school of your dreams, how would digital technologies be used in the most effective and efficient ways?

I think that technology has to be transparent. When we use technology, the learning curve must not be too steep in order for the learning to remain the focus of what's happening in the school. Technology can be a big component of what's happening in the classroom, but if we use technology also in a way that it helps out with the logistics of the work being done, that's a very transparent use of technology. Right now, many students still have big school bags. If we could have more e-books or digital books ... but the technology is there for that. I'd love to see in schools where kids don't have school bags, and I would love for a principal to have that as an objective and try to see how that would be possible. Kids are still using agendas-why is that when we have the technology that can do even better than using physical agendas? There are a lot of things that have to be rethought. I would love for schools to have technologies that work. One of the reasons why many teachers don't want to use technology is that they 
get discouraged very easily when they want to use it and it's not working. I would like teachers to be exposed to what they can do that integrates the technology. Many teachers have no clue-some teachers want to use the technology, but they don't know what to do: they don't get it. How can we help them much more than what we're doing right now? I would love the schools to have a different structure in terms of how the day is organized. We have all those 50- and 60-minute periods-can we change all of that? Can we break ... even physical walls ... something major has to be done with schools. The schools that we have still reflect the philosophy of another era. It's not at all linked to the learning that should be happening in schools. There is a lot of work done in flexible learning spaces lately and it's not about having a cool class that looks good-it's about removing obstacles to the kind of learning that we want to see happening in the schools today. Even the way technology is used or placed-where it is in the schools_sometimes is problematic. What are we still doing with computer labs? It's better to have a computer lab than not have any, but it would be great if we had a variety of access to technology. If there could be more computers, tablets, and Chromebooks in the classrooms, it would help so much more because the students would be able to use technology when they need it, not Friday, Period 5.

You have a daughter who is eight who came to an education camp recently. What do you know about technology integration because of having a daughter that you might not otherwise know?

Because of my daughter I know about what appeals to kids. Especially with social media and YouTube videos, she's always asking me when we're at Rona, Walmart, or whenever we're at a store, "Oh, can you buy this or can you buy that?" because of something that she saw on the Internet. And it's very often beautiful: she comes up with those great ideas triggered by videos that she's watched, but there's a whole world of YouTubers that are extremely powerful in terms of reach throughout the planet. You look at their videos and they have four, five, or 10 million views ... people all over the world are watching what these people are doing ... it's a testimonial to how powerful social media is. I'm glad because she loves DIY videos-that's all she pretty much does when she's on YouTube. But it's a very positive relationship with social media because it translates into things that she can do in real life. I was surprised_-and speaking to other parents that have kids the same age_-it's the same for their kids as well. They all know the same people on the Internet and they use the same craft techniques.

Slime ${ }^{7}$ right now is huge: how to make slime and there are so many different techniques. My daughter just goes on the Internet and looks for those resources. I am surprised to see how powerful social media is for students. I am happy to see that in her class they're using a few technologies that I've been showing to teachers. The other day my daughter came home and she wanted to do a Kahoot, ${ }^{8}$ which is a student-response system where you see a question that appears and you have to answer with some kind of technology. If I wasn't in the domain I wouldn't know about that. Because I'm in the field I pretty much know already what she's going to show me, but I can imagine that many parents would be very surprised by what their kids are showing them that exists out there. 


\section{Notes}

1. RÉCIT stands for Réseau • Éducation • Collaboration • Innovation • Technologie.

For more information: http://www.recit.qc.ca

http://www.learnquebec.ca/the-recit-network

https://www.youtube.com/watch?v=1QLevM3xgjg\&t=6s

2. For more information: http://www.education.gouv.qc.ca/adultes/formation-generaledes-adultes/

3. For more information: http://www.recitus.qc.ca/nouvelles/audioguides

4. For more information: https://en.wikipedia.org/wiki/QR_code

Examples of scanning QR codes: http://bit.ly/2AmsivA

5. For more information: http://recitdesarts.wixsite.com/histoiremanga

View examples: https://drive.google.com/open?id=1sF4HebrAI0D78fOE6-

$\underline{\text { OmHv0EJAA8KIsO }}$

6. For more information: http://novemberlearning.com/educational-services/educationalconsultants/alan-november/

7. For more information: https://www.highsnobiety.com/2017/06/15/slime-trend/

8. For more information: https://kahoot.com/

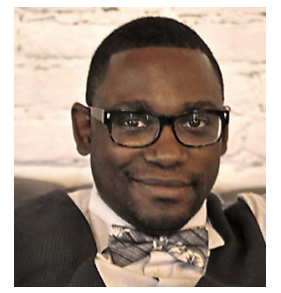

Kish Gué has worked in the education sector for over 19 years. He spent a large part of his career teaching at the elementary level and also has taught in high schools and adult education programs. For the last seven years, Kish has been supporting teachers as an Information and Communication Technology Pedagogical Consultant for the English Montreal School Board. Kish gives conferences and workshops on a regular basis and enjoys spending time with teachers and students in the classroom. He is passionate about promoting the pedagogically grounded integration of technology. 